\title{
An assessment of the marine turtle fishery in Grenada, West Indies
}

\author{
S. Grazette, J.A. Horrocks, Paul E. Phillip and Crafton J. Isaac
}

\begin{abstract}
The marine turtle fishery of Grenada was assessed using interviews with marine turtle fishermen and by examination of turtle catch data from a major landing site. An estimated 782 turtles, mainly Endangered green turtles Chelonia mydas and Critically Endangered hawksbill turtles Eretmochelys imbricata, were caught around Grenada and its sister island Carriacou each year between 1996 and 2001 during an annual 8-month open season, with only a small percentage being officially recorded at a landing site. Turtles were primarily caught with nets and spearguns, with more green turtles caught by net fishermen and more hawksbill turtles by spear fishermen. Catch per unit effort data suggested that relative abundance had declined since the previous estimate was made in 1969. Few adult green or loggerhead turtles Caretta caretta were caught,
\end{abstract}

indicating the relative scarcity of this size class of these two species around Grenada. Adult-sized hawksbill turtles were caught regularly, with larger adults being caught in the non-breeding months of the open season than in the breeding months. A higher percentage of adult hawksbill turtles present during the breeding season are likely to be animals that nest in Grenada, and their smaller size may result from historically heavy fishing pressure. The larger sized adults caught during the non-breeding season are likely to be animals that forage around Grenada but breed elsewhere in the Caribbean where they are protected.

Keywords Caretta caretta, Chelonia mydas, Eretmochelys imbricata, fishery, green turtle, Grenada, hawksbill turtle, loggerhead turtle.

\section{Introduction}

The island of Grenada, the neighbouring island of Carriacou, and the intervening islands that together make up the island nation of Grenada provide an abundance of sea grass and coral reef foraging habitats for Endangered green turtles Chelonia mydas and Critically Endangered hawksbill turtles Eretmochelys imbricata (IUCN, 2006), as well as sandy beaches suitable for nesting by hawksbill, Critically Endangered leatherback turtles Dermochelys coriacea (IUCN, 2006), and green turtles (Carr et al., 1982). Nearshore green and hawksbill turtles, and further offshore loggerhead turtles Caretta caretta, occur in Grenada's waters year-round but leatherback turtles visit only seasonally to breed. Nesting by green turtles was reported by Finlay (1984) but Carr et al. (1982) and current opinion (R. King, pers. comm.) suggest that it occurs rarely. Whether, and to what

S. Grazette and J.A. Horrocks (Corresponding author) Department of Biological and Chemical Sciences, University of the West Indies, Cave Hill Campus, Barbados, West Indies. E-mail horrocks@uwichill.edu.bb

Paul E. Phillip and Crafton J. Isaac Fisheries Division, Ministry of Agriculture, Lands, Forestry and Fisheries, Church Street, St. George's, Grenada, West Indies.

Received 21 June 2005. Revision requested 8 December 2005. Accepted 1 April 2006 extent, loggerhead turtles nest in Grenada is disputed (Rebel, 1974; Carr et al., 1982; Finlay, 1984).

Fishing for marine turtles in Grenada has been an important activity since the island nation was first inhabited (Meylan \& Mack, 1983). Much of the fishing occurs in the shallow waters around the Grenadines and along the north, east, and south coasts of Grenada. These shallow areas are characterized by coral reefs, sea grass beds and sandy substrates, often with adjacent nesting beaches. Turtle fishing on the west coast of Grenada is less common because the shallow shelf area is narrow, quickly sloping off into deep water.

The primary species harvested in Grenada have traditionally been green and hawksbill turtles (Groome, 1970). The meat of these two species is favoured over the stronger taste of loggerhead and leatherback turtles (Finlay, 1984) but the eggs of all marine turtle species are considered a traditional delicacy. Turtles are a valuable fishery resource, especially the hawksbill turtle whose shell is sold on the local market (Eckert \& Eckert, 1990) and formerly on the international market. Prior to the end of international trade in hawksbill products, hawksbill turtles were primarily targeted for their shells, which generated considerably more revenue than their meat.

At least 973 green and hawksbill turtles were caught in 1948 by 92 part-time fishermen in 8-10 boats operating 32 nets (approximately 30 turtles per net; Rebel, 1974). A Fishery Division survey in 1969 estimated that c. 600 
turtles were caught using about twice the effort (61 nets; approximately 10 turtles per net; Rebel, 1974), suggesting that turtle abundance had declined by approximately a third in the intervening years. A follow-up survey in 1981 estimated that about 1,000 turtles were caught annually, but only c. 400 were brought to landing sites (Finlay, 1984). The number of fishermen, all of whom were part-time, was reported as $50 \pm 10$, but the number of nets in use was not recorded.

Turtles in Grenada are now typically caught in nets set by boat fishermen or by skin and Scuba divers using spearguns, and less commonly by boat fishermen using grips (a metal hook attached to a wooden rod) to catch basking turtles. Most turtle fishermen do not fish for marine turtles on a full-time basis but turtle meat is still popular, especially for occasions such as christenings, weddings or work parties (J. St Louis, pers. comm.). There is currently a closed season during 1 May-31 August for all species except for the leatherback, which is now protected year-round. The closed season covers the peak nesting seasons for hawksbill and green turtles, but adult hawksbill turtles are not protected during breeding months that fall outside the closed season. Catching of hawksbill and green turtles below $30 \mathrm{lb}$ $(13.6 \mathrm{~kg})$ and loggerheads below $25 \mathrm{lb}(11.4 \mathrm{~kg})$, and the taking of eggs of all species is prohibited at all times.

Despite the abundance of critical foraging habitats and a long history of marine turtle exploitation in the eastern Caribbean (Bacon, 1981; Carr et al., 1982), little information on the fisheries targeting marine turtles is available to inform appropriate management for sustainable use (but see Godley et al., 2004). Although a survey of marine turtles caught in Grenada has not been conducted since 1981 (Finlay, 1984), data have been collected since 1996 by the Government of Grenada's Fisheries Division on the numbers of marine turtles landed at the primary east coast landing site at Grenville. The objective of this paper is to characterize the current marine turtle fishery in Grenada through interviews with turtle fishermen and through the examination of 5 years of marine turtle landing data.

\section{Methods}

Grenada, in the south-eastern Caribbean, consists of two main islands, Grenada and Carriacou, and several small unoccupied islets (Fig. 1). Thirty-two turtle fishermen were interviewed at eight coastal locations (five in Grenada and three in Carriacou) in September 2001 as part of a study on harvest and trade of marine turtles in the eastern Caribbean (Grazette, 2002). The fishermen interviewed had been fishing for marine turtles for an average of 21 years (range 1-78 years). A structured questionnaire with closed ended questions but with an 'other' option for some questions, was used for each interview. The questions focused on experience of fishing for turtles, fishing effort and methods used, and the use and marketing of turtle products. All the interviews were conducted by SG, who began by introducing herself as a student of the University of the West Indies, and informing each fisherman that she was conducting a project to increase knowledge of the status of sea turtles in Grenada to guide management of the resource. Fishermen were not required to provide their names and all participated willingly in the opportunity to present their traditional knowledge and perspectives on the sea turtle fishery.

The data on marine turtles landed at Grenville market were collected by Fisheries personnel during the open seasons of 1996-2001. Turtle meat is sold at other markets and landed at several other sites, but statistics are only recorded at Grenville, which is the largest market. Grenville is located $11 \mathrm{~km}$ from the capital, St George's (Fig. 1). Turtles landed at Grenville are captured from as far as Carriacou to the north and Point Salines to the south. However, most of the turtles are caught between $5 \mathrm{~km}$ to the north and $10 \mathrm{~km}$ to the south of Grenville (S. Grazette, pers. obs). Fisheries personnel at Grenville recorded the species caught, the location of capture, the shell length (curved carapace length, CCL, measured in $\mathrm{cm}$ with a flexible tape), weight, and the method of capture.

\section{Results}

\section{Interviews with fishermen}

All fishermen interviewed regarded eating turtle meat as an important part of Grenada's traditions, and all considered turtle meat to be an important component of their diet. Most respondents $(n=20 ; 62.5 \%$ ) fished for turtles in nearshore reef or sea grass habitats. The remainder reported fishing in open water over sand, often on their way to, or returning from, fishing for surface pelagic fish species. The type of fishing gear used to catch turtles varied depending on the habitat type. Nets were set both when fishing over sand and in sea grass habitats, but typically not over reef habitat. Spearguns were used both in sandy areas and reef habitats. Of the fishermen interviewed 18 (56.3\%) used nets, operating a total of 49 nets between them. Of the remaining 14 respondents, 13 (92.9\%) used a speargun only or a speargun and grip, and one reported taking nesting females from the beach. The average number of years spent fishing for turtles using nets and spearguns (or spearguns and grips) was 22.5 and 19.7 years respectively, but the difference was not significant $(t=0.45, \mathrm{P}>0.05)$. 


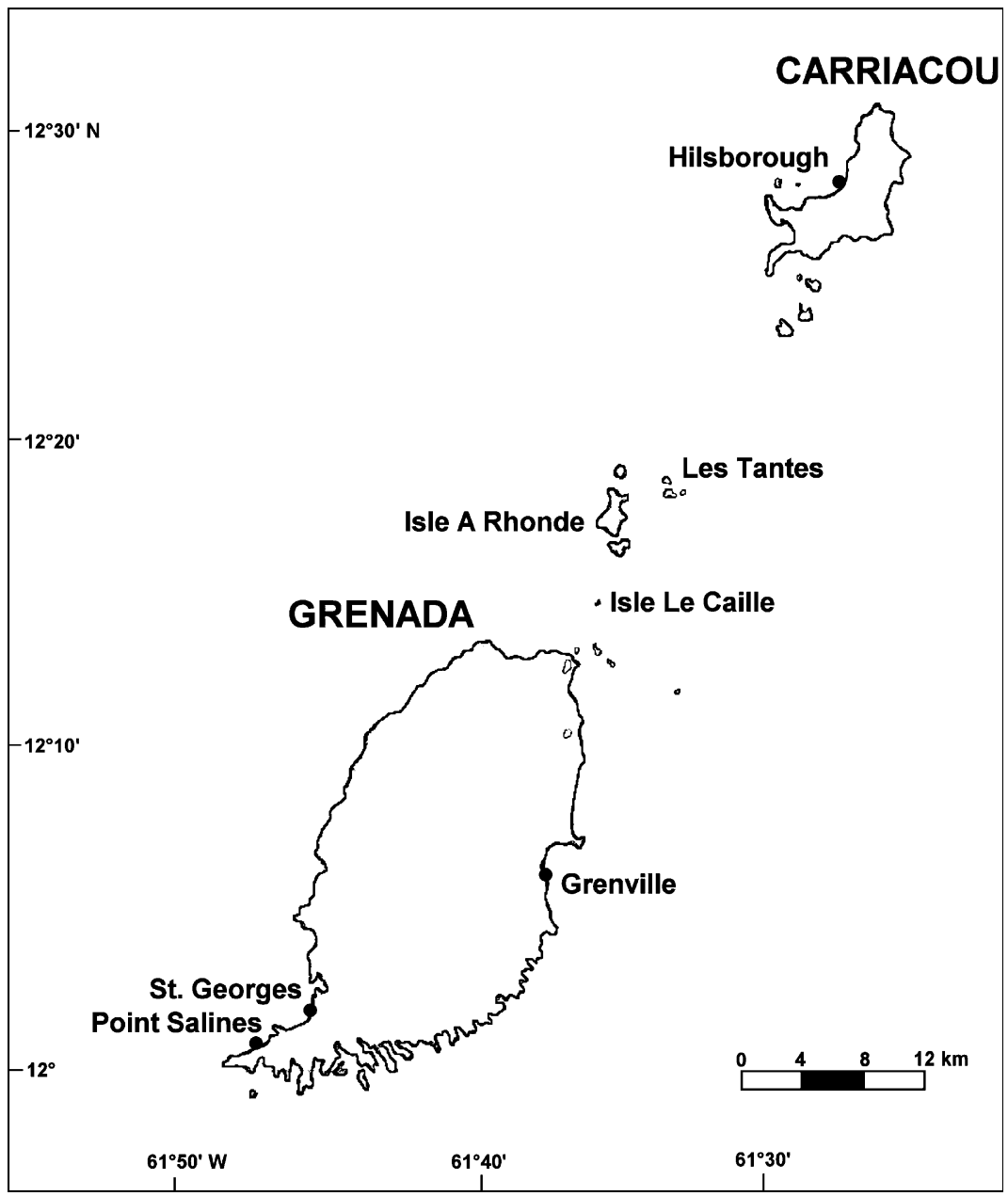

Fig. 1 A map of the islands of Grenada and Carriacou, showing the capital St. George's and Grenville market.
The fishermen interviewed reported taking an estimated total of 782 turtles per year, combined for all fishing methods used. Net fishermen reported catching an average of 364 turtles year $^{-1}$ between them (20.2 turtles person ${ }^{-1}$ year $^{-1}$ ) or an average of 7.4 turtles net $^{-1}$ year $^{-1}$. Most of these were green turtles $(n=227 ; 62.4 \%)$, with considerably fewer hawksbill turtles $(\mathrm{n}=85$; $23.4 \%$ ). Loggerhead turtles made up the remainder of the catch. Only two of the 18 net fishermen interviewed $(11.1 \%)$ reported having their catch recorded at a landing site. Spear and grip fishermen combined $(n=13)$ reported catching an average of 418 turtles year $^{-1}$ between them or 32.2 turtles person $^{-1}$ year $^{-1}$. Of these, most were hawksbill $(217 ; 51.9 \%)$ and green turtles $(181 ; 43.3 \%)$, and the remainder loggerhead turtles. The fisherman who took nesting turtles from the beach took $<5$ per year. Eight of these 14 respondents (57.1\%) reported having their catch recorded at a landing site.

The majority of fishermen interviewed ( $\mathrm{n}=28$; $85.7 \%$ ) butchered their own catch and sold the meat, and the remainder ate it themselves or gave the meat to friends and family. There were no reports of eggs being sold by fishermen, suggesting that, when eggs are taken, they are all consumed by family and friends. Although half of the fishermen reported throwing the shells away, the remainder stored at least some in the hope they may be able to sell them in the future. Scutes, or shell plates, were typically removed from adult hawksbill turtles, whereas the whole shells of green turtles were stored.

The majority (96\%) of the 25 fishers responding to questions about whether they had noticed changes in the size and numbers of turtles they had caught over time reported they had noticed no change in size, with most reporting average individual turtle catch weights of 100-200 lb (46-91 kg). Eighty-eight percent reported detecting no change in the numbers of turtles over the years they had been fishing.

\section{Landing statistics}

Of the 404 turtles recorded at Grenville market by Fisheries personnel, 145 were loggerhead, 131 green, 123 hawksbill, and 5 were olive ridley turtles Lepidochelys olivacea. The small number of olive ridley turtles was 
excluded from subsequent analyses. Most green and hawksbill turtles landed were caught during SeptemberDecember (the first 4 months of the turtle open season which begins on 1 September), whereas most loggerhead turtles were caught during January-April (the last 4 months of the turtle open season, which ends on 30 April; Fig. 2). There were no clear annual trends in numbers of loggerhead or hawksbill turtles landed, but numbers of green turtles were substantially higher in 1996/1997 than in subsequent years (Fig. 3). The mean size of animals caught each season over the 5-year period did not differ significantly for any of the three species (ANOVA; loggerhead, $F=2.2$; green, $F=1.8$; hawksbill, $F=1.1 ; \mathrm{P}>0.05$ in all cases).

The frequency distributions of the size of loggerhead, green and hawksbill turtles landed in the first 4 months (September-December) and last 4 months (JanuaryApril) of the open season are given in Fig. 4. For loggerhead and green turtles, the average sizes landed between September and December $(72.9$ and $68.1 \mathrm{~cm}$ CCL, respectively) did not differ significantly from the average sizes landed between January and April (72.1 and $69.1 \mathrm{~cm} \mathrm{CCL}$, respectively; $t=-0.23$ and $t=-0.37$; $\mathrm{P}>0.05$ in each case; Figs. $4 \mathrm{~A}$ and $4 \mathrm{~B})$. In contrast, the average size of hawksbill turtles landed between September and December $(71.2 \mathrm{~cm}$ CCL) was significantly smaller than the average size landed between January and April $(78.8 \mathrm{~cm} \mathrm{CCL} ; t=2.62, \mathrm{P}=0.01$; Fig. 4C).

\section{Discussion}

In 1948694 green, 279 hawksbill and two loggerhead turtles were exported from Grenada to Barbados and Trinidad (Rebel, 1974). At that time there were 8-10 boats operating 32 nets. This suggests that a minimum of 30 turtles per net were caught that year, assuming that

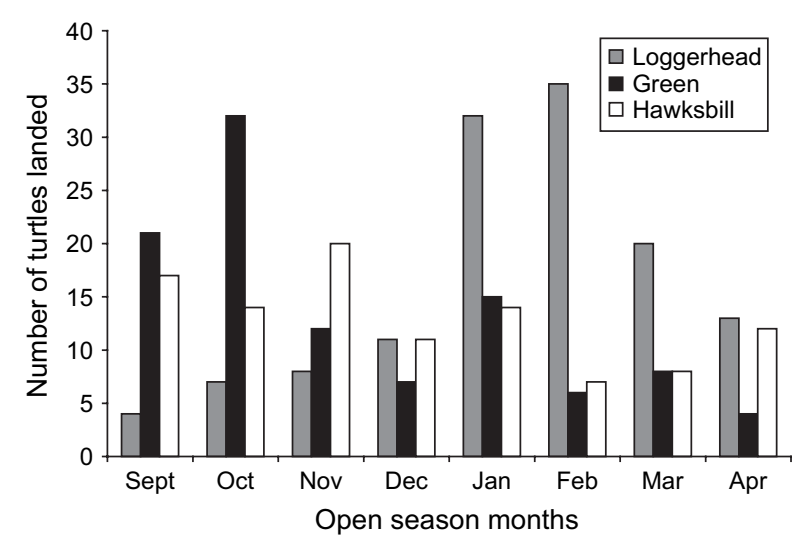

Fig. 2 The total number of loggerhead, green and hawksbill turtles landed at Grenville each month during the open seasons of $1996 / 1997$ to $2000 / 2001$.

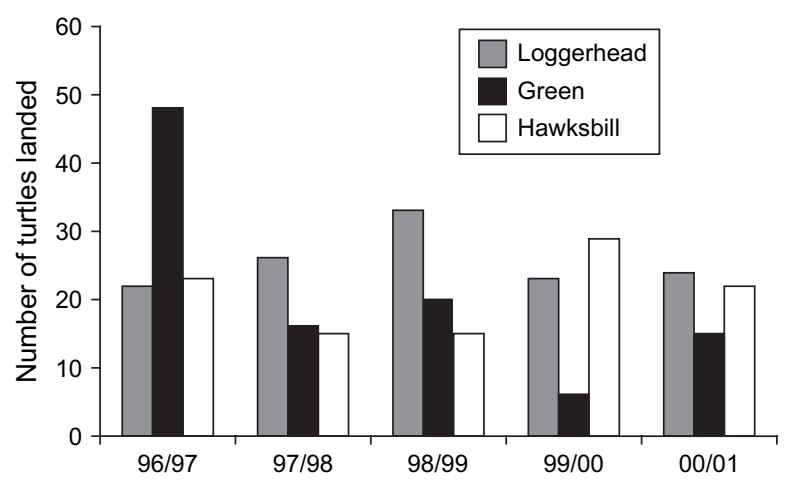

Fig. 3 The total number of loggerhead, green and hawksbill turtles landed at Grenville during the open seasons from 1996/1997 to $2000 / 2001$.

additional turtles were caught for domestic consumption (Rebel, 1974). Catch per effort had dropped to about one third of this by 1969 , i.e. about 10 turtles per net year ${ }^{-1}$. The data presented here suggest that abundance has declined further, with an average of 7.4 turtles being caught per net year ${ }^{-1}$. Despite this, most turtle fishermen interviewed considered that the numbers of turtles they caught had not declined over their years of fishing. However, because the decline in abundance was smaller between 1969 and 2001 than it was between 1948 and 1969, and because the average fisherman interviewed had been fishing for turtles for $<25$ years, it is not unreasonable to expect they may have been unable to detect a decline in abundance.

The 404 turtles recorded at Grenville market during 1996-2001 was substantially less than the number caught, as reported by the fishermen interviewed. Moreover, the recorded catch at Grenville consisted primarily of loggerhead turtles, rather than the green and hawksbill turtles that most of the fishermen interviewed reported as their more common catch. Most loggerhead turtles were landed at Grenville between January and April, whilst most green and hawksbill turtles were landed between September and December. This pattern may not reflect any seasonality in abundance but probably that fishermen who landed marine turtles at Grenville were involved in other fisheries between January and March each year, particularly the surface pelagic fisheries for dolphin Coryphaena hippurus, wahoo Acanthocybium solandri and kingfish Scomberomorus maculatus. Once the pelagic fishing season is over fishermen typically concentrate on fisheries that are associated with nearshore reefs and sea grass beds, where hawksbill and green turtles are relatively abundant. Since loggerhead turtles are typically found further offshore than hawksbill and green turtles, they may be caught opportunistically on pelagic fishing trips. 

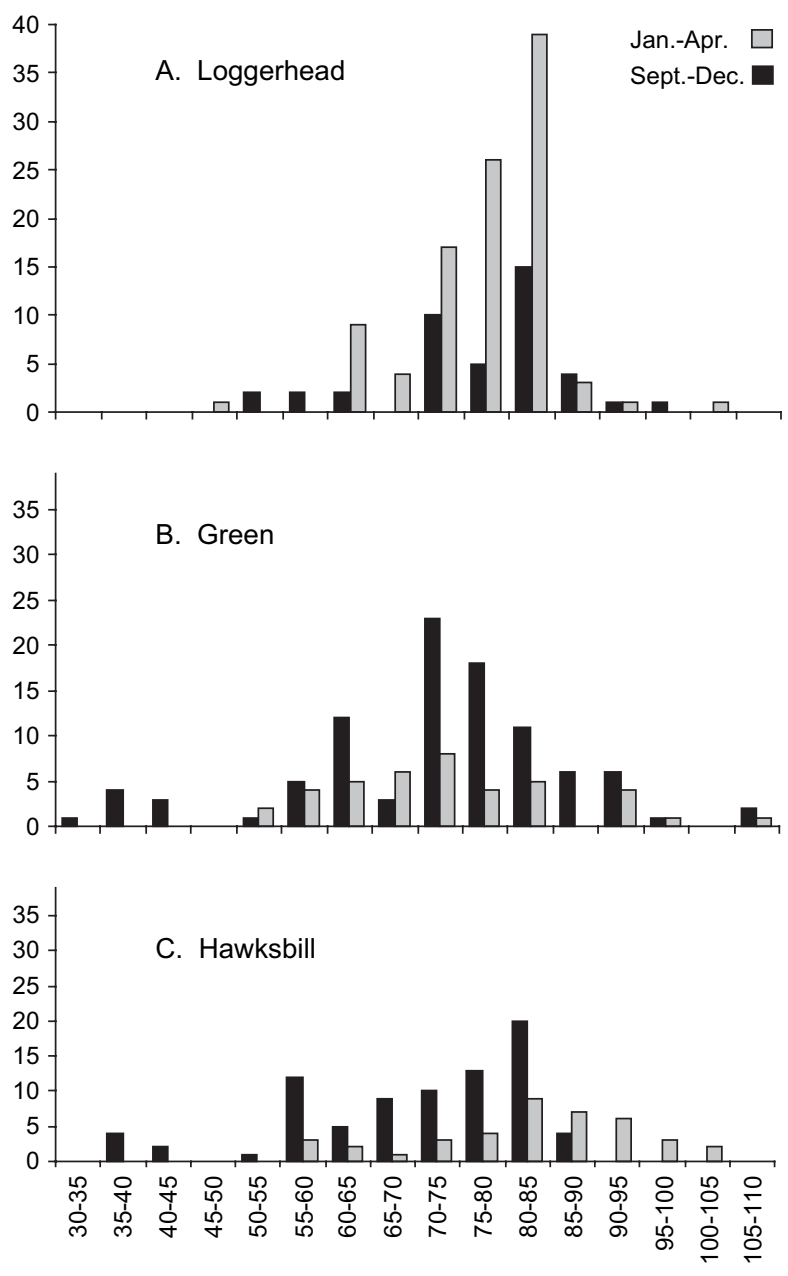

Curved Carapace Length $(\mathrm{cm})$

Fig. 4 Size frequency $(C C L \mathrm{~cm})$ distributions of loggerhead (A), green (B) and hawksbill (C) turtles landed at Grenville in the first (September-December) and last 4 months of the open season (January-April). Note the different axis scales.

The average size of loggerhead and green turtles landed at Grenville were in the subadult size range, with only four individual loggerhead and five individual green turtles above the minimum length of nesting turtles recorded in the Atlantic (loggerhead, $88.5 \mathrm{~cm}$ CCL; Dodd, 1988; green, 95.0 cm CCL; Bjorndal \& Carr, 1989). Of the 123 hawksbill turtles landed, 67 (54.5\%) were above the minimum size of nesting hawksbill turtles recorded elsewhere in the eastern Caribbean (76 cm CCL; J. Richardson, pers. comm.; Barbados Sea Turtle Project, University of the West Indies, unpubl. data).

A higher percentage of spear fishermen had their catch recorded than net fishermen, but the figures suggest that a large percentage of the catch is not recorded in either case. It is possible that the size class of the catch landed and recorded at Grenville may be biased towards larger size classes for two reasons. Firstly, spear fishing is more size selective than net fishing and may preferentially target larger turtles, and the catch of spear fishermen is more frequently recorded at Grenville than that of net fishermen. Secondly, as it is illegal to catch green and hawksbill turtles of $<30 \mathrm{lb}$ and loggerhead turtles of $<25 \mathrm{lb}$ smaller size classes will not be taken to the market when they are caught by either fishing method.

Despite the fact that the catches landed at Grenville may be biased towards larger size classes, the size composition of green and loggerhead turtles landed indicates that the catch consists mainly of subadults rather than adults. Moreover, this size composition remained constant over the period for which data were available, indicating consistently fewer adults than subadults around Grenada, at least during the open season. Loggerhead turtles of subadult size and smaller are common around Grenada (Carr et al., 1982) and therefore the predominance of these size classes in the landings is to be expected. However, very large green turtles (>700 lb, >317 kg) have been reported in Grenada's waters in former years (Carr et al., 1982), and nesting by green turtles was probably much more frequent in the past (Finlay, 1984). The lack of large green turtles being landed now suggests that adult-sized green turtles are currently rare around Grenada.

The size composition of hawksbill turtles landed, however, indicates that a substantial portion of the catch is of adult size, with larger adults being landed in January-April than September-December. The closed season (1 May-31 August) encompasses the peak of the green and hawksbill turtle nesting season, but significant nesting of hawksbill turtles still occurs into OctoberNovember. This latter part of the year is also when overall fishing effort for turtles is greater, as many fishermen begin fishing for turtles in nearshore habitats.

Hawksbill turtles breed every 2-3 years (Richardson et al., 1999) and satellite-tracking studies in the Caribbean have shown that the nesting beaches and foraging grounds of individual hawksbill turtles are typically separated by several hundreds or even thousands of $\mathrm{km}$ (Horrocks et al., 2001; Troeng et al., 2005). This knowledge can assist in the interpretation of seasonal differences in adult hawksbill turtle sizes observed in this study; specifically that the larger adults present in the January-April landings are largely absent from the September-December landings. During the open season hawksbill breeding months (September-November) the adult population will consist largely of animals that are breeding in Grenada that year, along with smaller numbers of non-breeding adults that forage around Grenada but breed elsewhere in the Caribbean. However, in the non-breeding months of the open season 
(January-April) those animals that bred in Grenada will no longer be present around the island, having left to return to their foraging grounds, and the adult hawksbill turtle population remaining is likely to be substantially composed of animals that have returned to foraging grounds around Grenada after breeding elsewhere. The aggregation of turtles in Grenada's waters targeted during the breeding season months of the open season is therefore different from that targeted in the non-breeding months.

The smaller size of adult hawksbill turtles caught in the breeding season months compared to those caught during the non-breeding months may be the consequence of historically heavier exploitation pressure on the former aggregation. With higher mortality rates, fewer animals survive to reach large sizes. If, in addition, mortality has been size-selective during these months and has historically targeted nesting females on the beaches or in inter-nesting habitats, this would lead to a further reduction in average size of adults. During the non-breeding months of the turtle open season (January-April) fishing effort for turtles is generally lower, and more adults from less heavily exploited nesting populations in the region are foraging in Grenadian waters. As a consequence, fewer but larger animals may be caught at this time. The average size of adult females nesting in Barbados, where nesting turtles have been protected since 1906, is $89.6 \mathrm{~cm}$ CCL (range 76-101 cm), and satellite tracking data and flipper tag returns confirm that a portion of the females that breed in Barbados forage around Grenada and Carriacou (Horrocks et al., 2001; Krueger et al., 2006). The average size of adults caught in the breeding months around Grenada is $79.8 \mathrm{~cm}$ while the average size of adults caught in the non-breeding months is $87.6 \mathrm{~cm}$.

Because adult female hawksbill turtles breed every 2-3 years on average we would still expect that some larger adult females, those that forage around Grenada and nest in other countries but are not undertaking breeding migrations back to the nesting beach that year, would be represented in the September-December catch. That very few larger non-breeding adults are caught during these months may suggest that, although in the vicinity of Grenada, they are not present in the nearshore habitats where fishermen tend to concentrate their fishing efforts at this time of the year. Tag recovery and satellite tracking data suggest that Barbados nesting females are often established on foraging grounds in deeper waters where they may be less accessible to nearshore fishermen (Horrocks et al., 2001).

The results of this study indicate that catch per unit effort of marine turtles around Grenada is now lower than in previous years, that adult green turtles are now scarce, and that the average size of hawksbill turtles nesting in Grenada appears to be smaller than protected nesting populations in neighbouring countries. These results emphasize the importance of continuing the systematic monitoring of sea turtle populations in Grenada and of strengthening the legislative framework to protect large juvenile and adult marine turtles (e.g. through minimum size limits, and by extending the closed season to encompass the entire breeding season; Horrocks 1992), thereby increasing the probability that abundance may increase and the exploitation of marine turtles around Grenada may become more sustainable.

\section{Acknowledgements}

We would especially like to thank Johnson St Louis, Junior McDonald, and Market managers Jerry St Louis and Emmanuel Joseph. We are also very grateful to Rebecca King, Carl Lloyd and Claire Shirley of Ocean Spirits, and Marina Fastigi of YWF-KIDO Foundation, Carriacou. Thanks to Wayne Hunte, Anne Meylan and an anonymous reviewer for improving an earlier version of the manuscript. Financial support came from an EU/Lomé grant to the University of the West Indies, Cave Hill Campus.

\section{References}

Bacon, P.R. (1981) The Status of Sea Turtle Stocks Management in the Western Central Atlantic. WECAF Studies No. 7. Interregional fisheries development and management program (WECAF component), UNDP and FAO, Panama.

Bjorndal, K.A. \& Carr, A. (1989) Variation in clutch size and egg size in the green turtle nesting population at Tortuguero, Costa Rica. Herpetologica, 49, 181-189.

Carr, A., Meylan, A., Mortimer, J., Bjorndal, K. \& Carr, T. (1982) Surveys of sea turtle populations and habitats in the Western Atlantic. NOAA Technical Memorandum (NMFS-SEFC), 91, 1-91.

Dodd, Jr, C.K. (1988) Synopsis of the biological data of the loggerhead sea turtle Caretta caretta (Linnaeus 1758). US Fish and Wildlife Service, Biology Report, 88(14).

Eckert, K.L. \& Eckert, S.A. (1990) Leatherback Sea Turtles in Grenada, West Indies: A Survey of Nesting Beaches and Socioeconomic Status. Report to the Foundation for Field Research and Fisheries Department, Ministry of Agriculture, Lands, Forestry and Fisheries, St George's, Grenada.

Finlay, J. (1984) National report for Grenada. In Proceedings of the Western Atlantic Turtle Symposium, 17-22 July 1983, San Jose, Costa Rica (eds P.R. Bacon, F. Berry, K. Bjorndal, H. Hirth, L. Ogren \& M. Weber), pp. 184-196. University of Miami Press, Miami, USA.

Godley, B.J., Broderick, A.C., Campbell, L.M., Ranger, S. \& Richardson, P.B. (2004) An Assessment of the Status and Exploitation of Marine Turtles in the UK Overseas Territories in the Wider Caribbean. Final Project Report to the Department of Environment, Food and Rural Affairs and the Foreign and Commonwealth Office, London, UK. 
Grazette, S. (2002) Harvest and national trade of sea turtles and their products in the Eastern Caribbean. MSc thesis, University of the West Indies, Cave Hill Campus, Bridgetown, Barbados.

Groome, J.R. (1970) A Natural History of the Island of Grenada. West Indies Caribbean Printers Limited, Trinidad.

Horrocks, J.A., Vermeer, L.A., Krueger, B., Coyne, M., Schroeder, B.A. \& Balazs, G. (2001) Migration routes and destination characteristics of post-nesting hawksbill turtles satellite-tracked from Barbados, West Indies. Chelonian Conservation and Biology, 4, 107-114.

IUCN (2006) 2006 IUCN Red List of Threatened Species. IUCN, Gland, Switzerland [http:/ /www.redlist.org, accessed 17 November 2006].

Krueger, B., Horrocks, J.A. \& Beggs, J.A. (2006) International movements of adult female and juvenile hawksbill turtles, Eretmochelys imbricata, from Barbados, West Indies. In Proceedings of the Twenty-Third Annual Symposium on Sea Turtle Biology and Conservation (compiler N.J. Pilcher), p. 230. NOAA Technical Memorandum NMFS-SEFSG-536.

Meylan, A. \& Mack, D. (1983) Sea turtles of the West Indies, a vanishing resource. Naturalist (Trinidad Naturalist Magazine), 4, 5-6, 45 .

Rebel, T.P. (1974) Sea Turtles and the Turtle Industry of the West Indies, Florida, and the Gulf of Mexico. University of Miami Press, Miami, USA.
Richardson, J.I., Bell, R. \& Richardson, T.H. (1999) Population ecology and demographic implications drawn from an 11-year study of nesting hawksbill turtles, Eretmochelys imbricata, at Jumby Bay, Long Island, Antigua, West Indies. Chelonian Conservation and Biology, 3, 244-250.

Troeng, S., Dutton, P.H. \& Evans, E. (2005) Migration of hawksbill turtles Eretmochelys imbricata from Tortuguero, Costa Rica. Ecography, 28, 394-402.

\section{Biographical sketches}

Stacia Grazette works in the Town Planning Department of the Government of Barbados reviewing the environmental impacts of coastal zone development.

Julia Horrocks has been studying sea turtles in Barbados and the eastern Caribbean for several years. Her main research interests include hawksbill nesting behaviour and ecology, and migratory behaviour.

Paul Phillip is Fisheries Officer and Marine Biologist with the Government of Grenada's Fisheries Division. Crafton Isaac is a Fisheries Assistant in the same Division. Both are responsible for the management and sustainable use of Grenada's marine turtle resources. 